\title{
Nanocrystal- and Dislocation-Related Luminescence in Si Matrix with InAs Nanocrystals
}

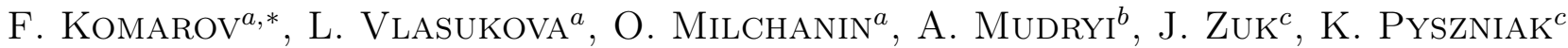 \\ AND M. KULIK ${ }^{c}$ \\ ${ }^{a}$ Belarussian State University, Nezavisimosti ave. 4, 220030 Minsk, Belarus \\ ${ }^{b}$ Scientific and Practical Materials Research Center, National Academy of Sciences of Belarus \\ P. Brovki Str. 17, 220072 Minsk, Belarus \\ ${ }^{c}$ Institute of Physics, Maria Curie-Skłodowska University, pl. M. Curie-Skłodowskiej 1, 20-031 Lublin, Poland
}

We have studied the influence of ion implantation and post-implantation annealing regimes on the structural and optical properties of silicon matrix with ion-beam synthesized InAs nanocrystals. (100) Si wafers were implanted at 25 and $500{ }^{\circ} \mathrm{C}$, subsequently with high fluences of As and In ions. After implantation the samples were processed by furnace and rapid thermal annealing at 900,950 and $1050{ }^{\circ} \mathrm{C}$. A part of the samples implanted at $25^{\circ} \mathrm{C}$ was additionally exposed to $\mathrm{H}_{2}^{+}$ions $\left(100 \mathrm{keV}, 1.2 \times 10^{16} \mathrm{~cm}^{-2}\right.$ in terms of atomic hydrogen). This procedure was performed to obtain an internal getter. In order to characterize the implanted samples transmission electron microscopy and low-temperature photoluminescence techniques were employed. It was demonstrated that by introducing getter, varying the ion implantation temperature, ion fluences and post-implantation annealing duration, and temperature it is possible to form InAs nanocrystals in the range of sizes of $2-80 \mathrm{~nm}$ and create various concentration and distribution of different types of secondary defects. The last ones cause in turn the appearance in photoluminescence spectra dislocation-related D1, D2 and D4 lines at $0.807,0.870$ and $0.997 \mathrm{eV}$, respectively.

PACS: 78.66.-w, 78.60.Fi

\section{Introduction}

A silicon based optoelectronics progress is restrained because of the absence of effective light source - light emitting diode or laser. The main problem is the indirect band gap nature of silicon, resulting in inefficient light emission. A number of approaches to overcome this problem were reported including the synthesis of $\mathrm{A}^{3} \mathrm{~B}^{5}$ quantum dots [1], or the controlled formation of structural defects in Si matrix $[2,3]$. In this work, we present the results of structural and optical characterizations of $\mathrm{Si}$ layers with ion-beam synthesized InAs nanocrystals.

\section{Experimental}

(100) Si wafers were implanted at 25 and $500^{\circ} \mathrm{C}$ subsequently with As and In ions. We have performed two types of experiment differing in ion implantation and post-implantation annealing regimes. In the first type of experiment Si samples were implanted with As $(245 \mathrm{keV}$, $\left.4.1 \times 10^{16} \mathrm{~cm}^{-2}\right)$ and In ions $\left(350 \mathrm{keV}, 3.7 \times 10^{16} \mathrm{~cm}^{-2}\right)$. Afterwards, the samples were annealed at $900{ }^{\circ} \mathrm{C}$ for

* corresponding author; e-mail: KomarovF@bsu.by
$60 \mathrm{~min}$. In the second type of experiment ion energies and fluences were reduced by a factor of 1.5. Accordingly, in this case silicon samples were implanted with $\mathrm{As}\left(170 \mathrm{keV}, 3.2 \times 10^{16} \mathrm{~cm}^{-2}\right)$ and In $(250 \mathrm{keV}$, $\left.2.8 \times 10^{16} \mathrm{~cm}^{-2}\right)$. After that, the implanted samples were annealed at 950 and $1050^{\circ} \mathrm{C}$ for $3 \mathrm{~min}$ using rapid thermal annealing (RTA). In the both experiments a part of the samples implanted at the room temperature was additionally exposed to $\mathrm{H}_{2}^{+}$ions $\left(100 \mathrm{keV}, 1.2 \times 10^{16} \mathrm{~cm}^{-2}\right.$ in terms of atomic hydrogen). This procedure was performed to obtain an internal getter at a depth of about $500 \mathrm{~nm}$ during post-implantation annealing. In both cases the annealing was carried out in an inert ambient gas.

A structure of the implanted samples was studied by means of transmission electron microscopy (TEM) in both plane-view (PV) and cross-section (X) geometry. The TEM investigations were performed using a Hitachi $\mathrm{H}-800$ instrument operating at $200 \mathrm{keV}$. The samples prepared for the TEM measurements have to be transparent for probe electron beam. It is possible if their thickness does not exceed 150-200 nm. For this reason for detailed investigations of deeper regions into crystal bulk we combined PV-TEM preparation with the precise removal of thin layers from the face surface of sample. 
The optical properties of samples were investigated by means of low temperature photoluminescence (PL). PL spectra were taken in the spectral region of 0.7 to $2 \mathrm{eV}$. The samples were mounted in a liquid He immersion cryostat. The $514.5 \mathrm{~nm}$ line of an argon ion laser was used to induce PL. The luminescence was dispersed by a $0.6 \mathrm{~m}$ grating monochromator and detected by a cooled InGaAs detector.

\section{Results and discussion}

TEM and PL results for the samples implanted with the higher ion fluence are presented in Fig. 1. For the sample implanted with As and In at room temperature with an additional implantation of $\mathrm{H}_{2}^{+}$, a thin layer of secondary defects (mostly dislocation loops) is recorded at a depth of approximately $500 \mathrm{~nm}$, around the $R_{\mathrm{p}}$ for $\mathrm{H}_{2}^{+}$ions (Fig. 1a). The formation of such defects is characteristic process of amorphous layer recrystallization.

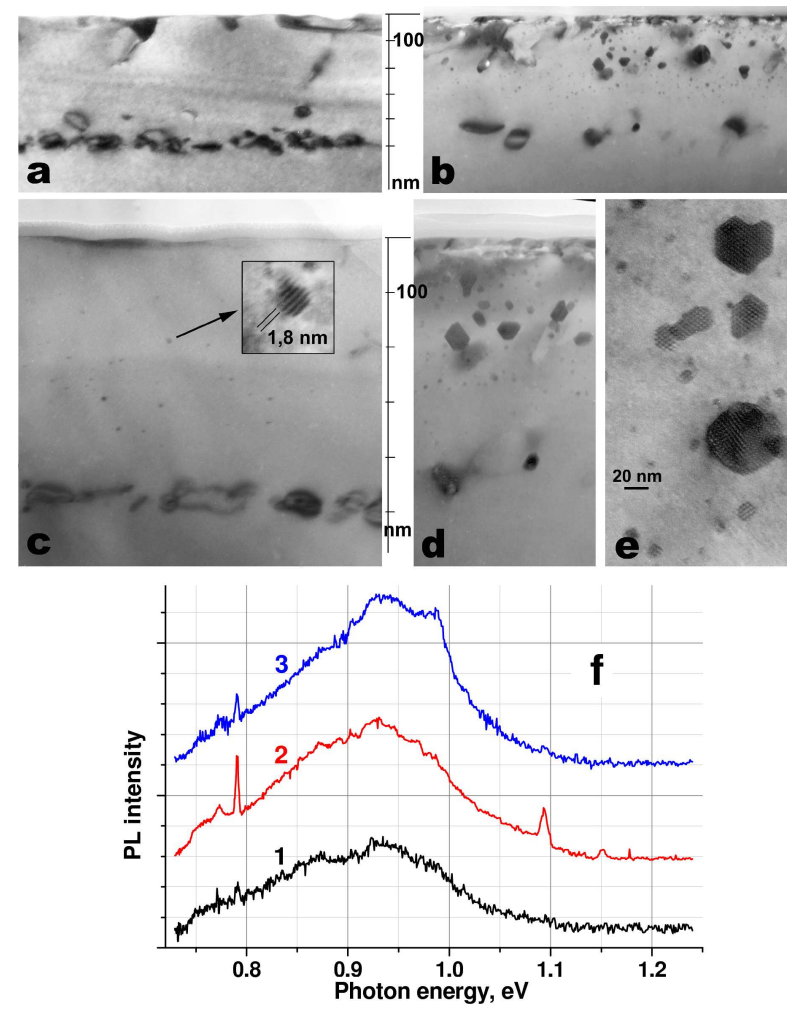

Fig. 1. TEM cross-section (a-d) and plan-view (e) images as well as PL spectra (f) of the silicon samples implanted with As $\left(245 \mathrm{keV}, 4.1 \times 10^{16} \mathrm{~cm}^{-2}\right)$ and In $\left(350 \mathrm{keV}, 3.7 \times 10^{16} \mathrm{~cm}^{-2}\right)$ and annealed at $900^{\circ} \mathrm{C}$ for 60 min. $t_{\text {impl }}=25$ (a, c, curves 1 and 2 in f) and $500^{\circ} \mathrm{C}$ (b, d, e, curve 3 in f). The samples with getter layer - a, c, curve 2 in $\mathrm{f}$. Inset in (c) represents an image of InAs precipitate taken at higher magnification.

At depths from 100 to $350 \mathrm{~nm}$, there are small precipitates from 2 to $10 \mathrm{~nm}$ in size. This region in the crystal corresponds to concentration maxima in the implanted impurity profiles simulated using SRIM-2003 code. A detailed study of the structure of these inclusions, according to the technique described in [1], allowed us to identify them as InAs nanocrystals. One can see from Fig. 1b that in the case of "hot" implantation two spatially separated layers of secondary defects are observed. The first defect layer containing micropores and microtwins is localized in the thin near surface region. In the deeper defect layer (400-450 nm), separate dislocation loops are recorded. Between these two defect layers, at the sample depth of $80-350 \mathrm{~nm}$, there is a defect-free silicon region containing InAs precipitates. Alongside the small clusters (from $2 \mathrm{~nm}$ ), considerably larger ones with sizes up to $80 \mathrm{~nm}$ are observed (Fig. 1b). Figure 1f depicts the PL spectra of implanted and annealed samples. For the crystals implanted at $25^{\circ} \mathrm{C}$, a broad band in a range of $0.75-1.1 \mathrm{eV}$ with a maximum of $0.93 \mathrm{eV}$ is detected in PL spectra. The intensity of this band is almost five times greater for the sample with a getter layer in comparison with one without getter (curves 2 and 1 in Fig. 1f, respectively). A phononless line of $0.79 \mathrm{eV}$ is observed in the spectrum, due to the recombination of bound excitons on ion induced defects (interstitial carbon-interstitial oxygen $\left(\mathrm{C}_{\mathrm{i}}-\mathrm{O}_{\mathrm{i}}\right.$ pairs $)$ [3]. For the samples implanted at $500{ }^{\circ} \mathrm{C}$, a broad band in the range $0.75-1.1 \mathrm{eV}$ with an extended low energy wing is also found in the PL spectra (curve 3 in Fig. 1f). The intensity of this band is four times greater than that of samples implanted at room temperature (Fig. 1f, curve 1).

Figure 2 shows TEM plan-view images and PL spectra of samples implanted with the lower fluence after RTA at $1050{ }^{\circ} \mathrm{C}$ for $3 \mathrm{~min}$. On the plan-view images of the subsurface region up to depth of about 150-200 nm one can see nanocrystals. The size of nanocrystals varies in the range of about $5-40 \mathrm{~nm}$ as in the both samples with and without getter layer (Fig. 2a, c). On the depth of about 200-400 $\mathrm{nm}$ a layer of secondary defects is located (Fig. 2b, d). The existence of getter layer influences sizes and density of secondary defects. One can see that in the sample without getter layer there are large elongated and curved dislocation-like defects. There also should be noted disordered zones marked by arrows in Fig. 2d. The size of the largest disordered zones tends to $\approx 500 \mathrm{~nm}$. The getter layer creation results in a large number of small densely packed dislocation loops (Fig. 2b). As one can see from Fig. 2e, an intense band at $1.09 \mathrm{eV}$ corresponding to the $\mathrm{Si}$ band-edge emission dominates the $\mathrm{PL}$ spectra. A broad band in a region $0.85-1.05 \mathrm{eV}$ is also detected. We may assume that this band is a superposition of at least two PL lines with maxima of about 0.960 and $0.995 \mathrm{eV}$. In the PL spectrum of the sample with getter an additional weak line with a maximum of $0.807 \mathrm{eV}$ is detected. The emission at $0.995 \mathrm{eV}$ and at $0.807 \mathrm{eV}$ coincides to the energies of so-called D1 and D4 lines and may be attributed to the presence of dislocations in implanted layers. The dislocation-related PL peaks with maxima at $0.807 \mathrm{eV}$ (D1) and at $0.870 \mathrm{eV}$ (D2) were detected in plastically deformed Si [4], Er- 


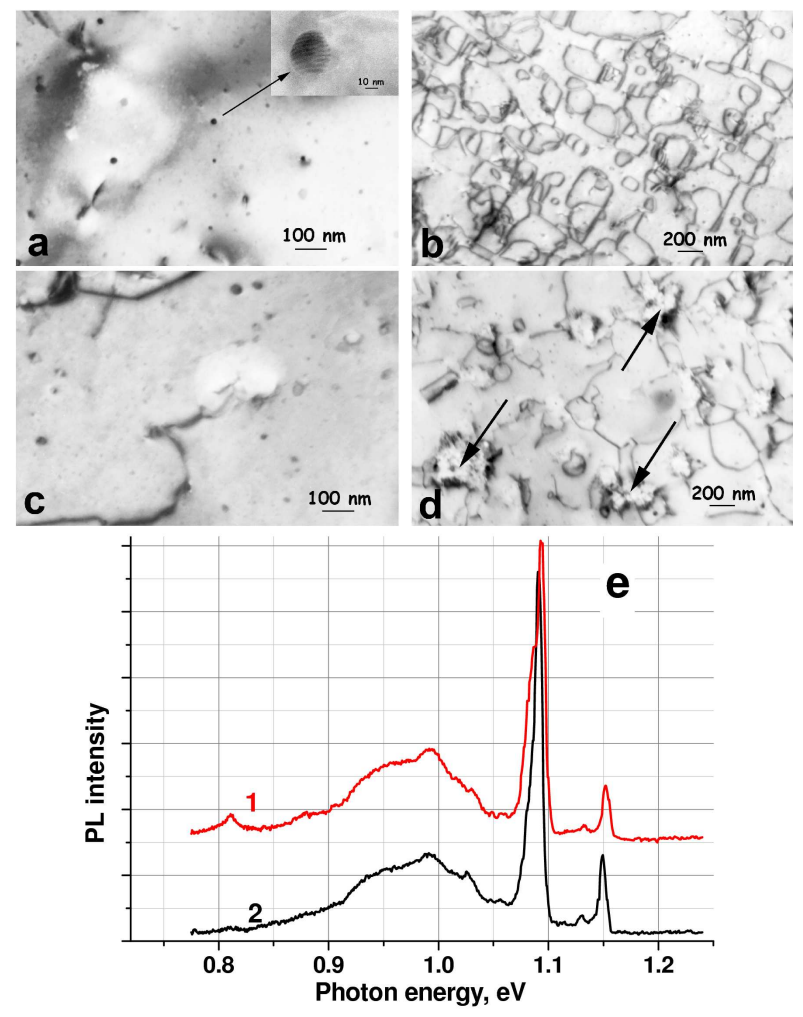

Fig. 2. TEM plan-view images $(\mathrm{a}-\mathrm{d})$ and PL spectra (e) of the samples implanted with As $(170 \mathrm{keV}, 3.2 \times$ $\left.10^{16} \mathrm{~cm}^{-2}\right)$ and In $\left(250 \mathrm{keV}, 2.8 \times 10^{16} \mathrm{~cm}^{-2}\right)$ at $25^{\circ} \mathrm{C}$ and annealed at $1050^{\circ} \mathrm{C}$ for $3 \mathrm{~min}$. The samples with getter layer ( $\mathrm{a}, \mathrm{b}$, curve 1 in e) and without getter layer (c, d, curve 2 in e). Inset in (a) represents a precipitates image taken at higher magnification.

-implanted silicon [3], relaxed epitaxial SiGe layers [5], laser-melted Si [6] and liquid-phase epitaxy Si [7]. The dislocation-related peaks at 0.935 (D3) and at $0.997 \mathrm{eV}$ (D4) were found in Si wafers after the formation of oxygen precipitates [8]. Photoluminescence at $0.960 \mathrm{eV}$ was detected for coherent InAs clusters on $\mathrm{Si}$ (001) fabricated by means of MBE-technique [9] and by means of high fluence implantation of $\mathrm{As}$ and In ions [1]. The appearance of PL signal at $0.960 \mathrm{eV}$ was attributed to the formation of InAs quantum dots in the silicon matrix.

TEM plan-view images and PL spectra for samples implanted with As $\left(170 \mathrm{keV}, 3.2 \times 10^{16} \mathrm{~cm}^{-2}\right)$ and In $\left(250 \mathrm{keV}, 2.8 \times 10^{16} \mathrm{~cm}^{-2}\right)$ at $500{ }^{\circ} \mathrm{C}$ and annealed at 950 or $1050^{\circ} \mathrm{C}$ for $3 \mathrm{~min}$ are presented in Fig. 3. It is worth to note that for "hot" implantation conditions nanocrystal size increases significantly in comparison with the implantation at $25^{\circ} \mathrm{C}$ (Fig. 3a, b; Fig. 2a, c). The largest precipitates have a size of about $100 \mathrm{~nm}$. The density of precipitates in "hot" implanted samples is also higher in comparison with the samples implanted at the room temperature.

In TEM patterns (insets in Fig. 3a, c) there are distinct reflexes from microtwins. It should be noted that in
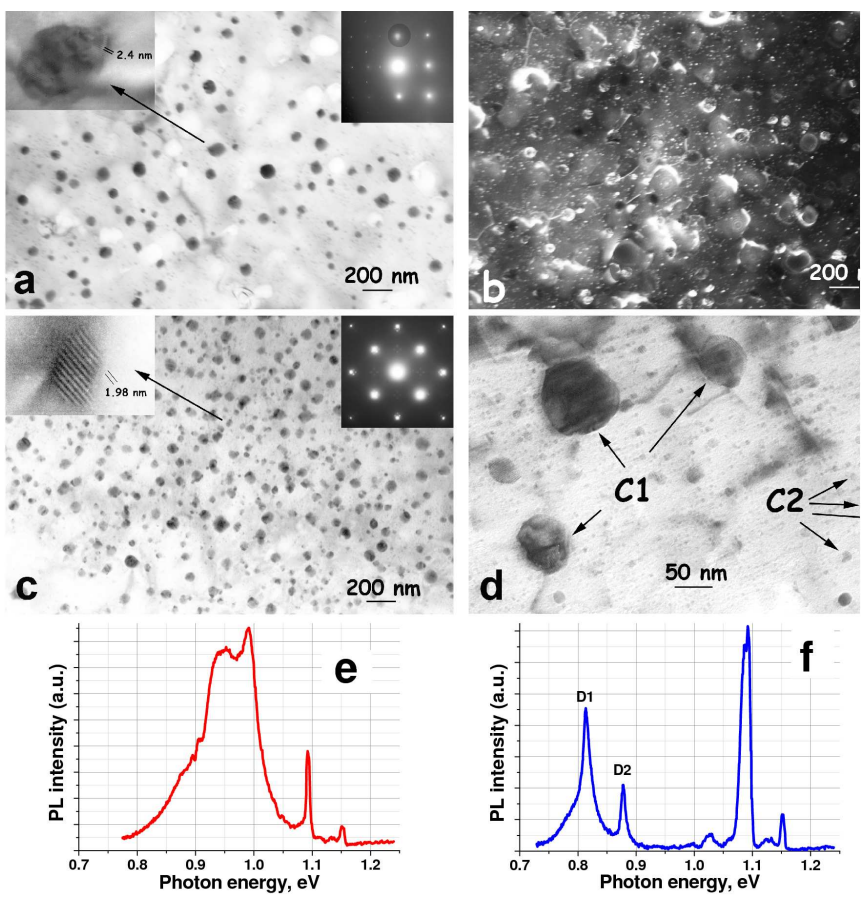

Fig. 3. TEM bright-field (a, c, d) and dark-field (b) plan-view images and PL spectra $(e, f)$ of the samples implanted with As $\left(170 \mathrm{keV}, 3.2 \times 10^{16} \mathrm{~cm}^{-2}\right)$ and In $\left(250 \mathrm{keV}, 2.8 \times 10^{16} \mathrm{~cm}^{-2}\right)$ at $500^{\circ} \mathrm{C}$ and annealed at 1050 (a, b, e) and $950^{\circ} \mathrm{C}(\mathrm{c}, \mathrm{d}, \mathrm{f})$ for $3 \mathrm{~min}$. Left-side insets in $(\mathrm{a}, \mathrm{c})$ are precipitates images taken at higher magnification.

the dark-field image precipitates sizes seem to be larger in comparison with bright-field image (Fig. 3a, b). This effect is caused of "glowing" of nanocrystal/Si matrix interfaces. One can see a great number of small $(2-5 \mathrm{~nm})$ clusters in the dark-field image (Fig. 3b).

Figure $3 \mathrm{~d}$ demonstrates a bimodal size distribution of nanocrystals in the samples annealed at $950^{\circ} \mathrm{C}$.

Figure $3 \mathrm{e}$ shows the PL spectrum of the sample annealed at $1050{ }^{\circ} \mathrm{C}$. As for the room temperature implanted sample, two lines are found in the spectrum. They are a narrow line at $1.09 \mathrm{eV}$ corresponding to the $\mathrm{Si}$ band-edge emission and a very intensive broad band in a region of $0.85-1.05 \mathrm{eV}$ with an extended low-energy wing. Unlike the room temperature implanted sample, in the sample after "hot" implantation the $1.09 \mathrm{eV}$ peak's intensity is lower in comparison with the band in the range of $0.85-1.05 \mathrm{eV}$.

Figure 3f shows the PL spectrum of the sample annealed at $950^{\circ} \mathrm{C}$ for $3 \mathrm{~min}$. Surprisingly, the reduction of the annealing temperature results in the rearrangement of photoluminescence signal and an appearance of intensive dislocation-related D1 and D2 bands at $0.807 \mathrm{eV}$ and $0.870 \mathrm{eV}$. An intensity of the Si band-edge emission related peak at $1.09 \mathrm{eV}$ increases while a broad band in a region of $0.85-1.05 \mathrm{eV}$ is not detected. It should be noted that in accordance with the TEM data there is no 
significant difference in the region with maximum density of nanocrystals for the samples annealed at 950 and $1050^{\circ} \mathrm{C}$

Further investigations to study the mechanism of structural-phase transformations in InAs nanocrystals/Si matrix system after RTA and to clear the nature of secondary defects resulting in the appearance of dislocation-related lines in PL spectra are in progress.

\section{Conclusions}

The influence of ion implantation and post-implantation annealing regimes on the structural and optical properties of silicon matrix with ion-beam synthesized InAs nanocrystals has been studied. It was demonstrated that the introduction of the getter layer and varying the post-implantation annealing duration and temperature may provide the way for controlled generation of secondary defects and the appearance in PL spectra of dislocation-related D1, D2 and D4 bands at $0.807,0.870$, and $0.997 \mathrm{eV}$, respectively.

\section{Acknowledgments}

This work was supported by the Belarussian Republican Foundation for Fundamental Research (grants F10R-143 and T10R-142).

\section{References}

[1] F. Komarov, L. Vlasukova, W. Wesch, A. Kamarou, O. Milchanin, S. Grechnyi, A. Mudryi, A. Ivaniukovich, Nucl. Instrum. Methods Phys. Res. B 266 3557 (2008)

[2] M.A. Lorenço, M. Milosavljević, R.M. Gwilliam, K.P. Homewood, G. Shao, Appl. Phys. Lett. 87, 201105 (2005).

[3] N.A. Sobolev, O.B. Gusev, E.I. Shek, V.I. Vdovin, T.G. Yugova, A.M. Emel'yanov, J. Lumin. 80, 357 (1999).

[4] V.V. Kveder, E.A. Steinmann, S.A. Shevchenko, H.G. Grimmeiss, Phys. Rev. B 51, 10520 (1995).

[5] S. Fukatsu, Y. Mera, M. Inoue, K. Maeda, H. Akiyma, H. Sakaki, Appl. Phys. Lett. 68, 1889 (1996).

[6] E.Ō. Sveinbjörnsson, J. Weber, Mater. Res. Soc. Symp. Proc. 422, 148 (1996).

[7] S. Binetti, M. Donghi, S. Pizzini, A. Kataldini, State Phenomena 57-58, 197 (1997).

[8] R. Sauer, J. Weber, J. Sholz, E.R. Weber, K.H. Kusters, H. Alexander, Appl. Phys. A 36, 1 (1985).

[9] R. Heitz, N.M. Ledentsov, D. Bimberg, R. Heitz, N.N. Ledentsov, D. Bimberg, A.Yu. Egorov, M.V. Maximov, V.M. Ustinov, A.E. Zhukov, Zh.I. Alferov, G.E. Cirlin, I.P. Soshnikov, N.D. Zakharov, P. Werner, U. Gösele, Physica E 7, 317 (2000). 